\title{
Development of a quantitative assessment approach for the coal and gas outbursts in coal mines using rock engineering systems
}

\author{
Qinglong Zhou ${ }^{\mathrm{a}, \mathrm{b}}$, Juan Herrera ${ }^{\mathrm{a}}$ and Arturo Hidalgo ${ }^{\mathrm{a}, \mathrm{c}}$ \\ aDepartamento de Ingeniería Geológica y Minera.ETS de Ingenieros de Minas y Energía, Universidad Politéncia de \\ Madrid, Madrid, Spain; 'bETS de Ingenieros de Minas y Energía, Universidad Politéncia de Madrid, Madrid, Spain; \\ 'Center for Computational Simulation, Universidad Politécnica de Madrid, Madrid, Spain
}

\begin{abstract}
In this study, a new approach is proposed and developed for evaluating the comprehensive outburst index (range between 0 and 100), which is a quantitative assessment approach and will enable us to better understand the risk degree of coal and gas outburst in coal mines. By selecting some typical risk-free and high-risk outburst mines from China as the evaluation targets, we assessed their comprehensive outburst indexes with the developed approach. The assessment results are fully consistent with the actual situations, which indicates that our new developed approach is reliable and can be recommended for applying in more coal mines.
\end{abstract}

\section{Introduction}

An outburst of coal and gas (hereinafter referred to as outburst) is defined as the rapid release of a large volume of gas in conjunction with the ejection of large amounts of coal, and possibly associated rock, into the working face or mine workings [1]. In a short period of time, the huge amount of accumulated gas energy and strain energy in the coal seam or strata will be released [2], and such process of energy releasing is unstable and always the start of tremendous catastrophes, at every moment, mining or excavating especially in those gassy mines which have poor and complex geological conditions is just like treading on thin ice, we do not know when the disaster will come.

Although in the past decades researchers have already noticed that outburst is a worldwide issue $[3,4]$ and emphasised the importance of controlling and predicting outburst in mines [5-9], until now the precise mechanisms [10-13] of outburst are still unresolved and predicting techniques continue to be unreliable because most of their research perspectives are just based upon empirical or semi-empirical hypotheses $[2,14]$.

To obtain the precise mechanisms of outburst is still difficult because it is not a univariate problem or quantifiable problem with clear parameters, so far engineers even have not known how many parameters should be used to comprehensively analyse outburst problems are appropriate, considering all parameters related to outburst such as geological structures, in situ stresses, rock properties, coal properties, gas properties, hydraulic conditions, mining conditions are unrealistic because a large number of parameters need to be considered and a huge amount of geological surveys and laboratory tests need to be conducted. To date, selecting primary parameters to rank and predict the risk degree of outburst has been the main focus to control outburst, the analytical methods such as artificial neural networks (ANN) $[15,16]$, 
fault tree analysis (FTA) [17], logistic regression (LR) [18] and analytic hierarchy process (AHP) [19] are the methods that have already been successfully applied in this field. Of course, for these mentioned approaches, there are lots of advantages about each of them, but their shortcomings also should not be ignored. For example, to the ANN method, automatically learning mapping relations between input parameters and output results through sample training is its greatest advantage, but it considers every input parameter with equal importance, which is inconsistent with practical engineering because in engineering systems not all parameters are dominant, some parameters are subordinate. For the other methods, although they consider the importance of each parameter through computing weighted coefficients for each parameter, they failed to consider the interacting actions between parameters, which is also inconsistent with practical engineering because parameters of engineering projects generally are not independent, interactions between parameters are always existent [20].

In this study, with the use of the rock engineering systems (RES) [20], we will develop a new approach for the risk assessment of coal and gas outburst. Our approach will take into account interactions between parameters and we consider the importance of each parameter only according to its interacting intensity in the system. In addition, through transferring the interacting intensity of each parameter into a weighted coefficient, we will develop a comprehensive quantitative coal and gas outburst index (simplified as comprehensive outburst index) to evaluate the degree of outburst risk, and some case studies will be conducted with typical mines selected from China. As the new developed quantitative index in this study use a numerical number to characterise the risk degree of coal and gas outburst, it will provide a clear standard to mining engineers to determine in which condition a mine or a working face should take outburst prevention measures.

\section{Current outburst problems in China}

According to the information reported from state administration of coal mine safety [21], 1044 outburst mines are distributed in 20 provinces, and $92 \%$ of them are mainly located in Guizhou, Hunan, Sichuan, Chongqing, Henan, Anhui, Yunnan and Shanxi provinces. In south China, outbursts are mainly related to high gas contend and complex geological conditions. The reason for the former is because most of coal seams belong to the interactive marine and terrestrial deposits which formed in a remote geological timescale and have a good gas-tightness property; after many times of tectonic movements, lots of faults and folds were generated and the coal seams and even the deposits are heavily damaged, generally speaking, the geological conditions in south China are more complex than in north China. In north China, outbursts are mainly related to high gas pressure, comparing to the south, the north needs to produce more coal yield to support the huge requirement of economic development because most of the heavy industries located in the north, which leads to the high intensity of coal mining and the rapid increase in mining depth; now mining depth in most mines is more than $600 \mathrm{~m}$; in such a mining depth, outbursts are always triggered by high gas pressure.

Table 1. Outburst accidents occurred in China in recent years.

\begin{tabular}{lllccc}
\hline & & \multicolumn{1}{c}{ Locations } & \multicolumn{1}{c}{ Diner } \\
No. & & \multicolumn{1}{c}{ Dates } & $\begin{array}{c}\text { Outburst coal } \\
(t)\end{array}$ & Outburst gas $\left(\mathrm{m}^{3}\right)$ \\
\hline 1 & Daping coal mine, Henan Province & 03 March 2016 & 2 & $1.1 \times 10^{3}$ & $5.231 \times 1^{4}$ \\
2 & Jiulishan coal mine, Henan Province & 27 October 2011 & 18 & $3.246 \times 1^{3}$ & $2.912 \times 1^{5}$ \\
3 & Yongshan coal mine, Jiangxi Province & 28 February 2015 & 4 & $1.381 \times 1^{3}$ & $1.38 \times 10^{4}$ \\
4 & Houxi coal mine, Chongqing City & 04 August2015 & 3 & - & - \\
5 & Sangshuping coal mine, Shanxi Province & 06 July 2015 & 4 & $5 \times 10^{2}$ & $1.123 \times 1^{4}$ \\
6 & Tonghua coal mine, Chongqing City & 05 May 2009 & 30 & $3 \times 10^{2}$ & $2.82 \times 10^{5}$ \\
7 & Zhengzhong coal mine, Guizhou Province & 08 August 2015 & 13 & - & - \\
8 & Xinxing coal mine, Heilongjiang Province & 17 December 2015 & 3 & - & - \\
9 & Qujiang coal mine, Jiangxi Province & 30 September 2013 & 2 & $4.05 \times 10^{2}$ & $3.648 \times 1^{4}$ \\
10 & Yushe coal mine, Guizhou Province & 25 May 2014 & 8 & $3.27 \times 10^{2}$ & $3.28 \times 10^{4}$ \\
11 & Xintian coal mine, Guizhou Province & 05 October 2014 & 10 & - & - \\
\hline
\end{tabular}


Until now, outburst accidents are still occurred frequently in China every year, in Table 1, we list some of the serious accidents occurred in recent years (note that in these table some boxes are not available because in our investigation we found that the accident statistics of some mines are not clear, these empty boxes will not have influence on understanding this study, and more detailed information about these mines will be listed in Table 6), as can be seen from the Table, volume of outburst gas involved in these accidents is more than $10^{4} \mathrm{~m}^{3}$ and corresponding volume of outburst coal is more than $10^{2} t$.

\section{Main factors influencing gas outbursts}

\subsection{Gas content}

Gas content plays a very critical role in coal and gas outburst and it consists of two parts, the absorbed gas on the internal coal surfaces and the free-state gas in the cleats. In general, there is a certain minimum gas content is needed if an outburst is to occur in a coal seam, due to the differences in coal strength, gas pressure, effective stresses and other factors, the critical value may be different in different mining conditions, but overall from the past decades of laboratory researches and field experiences all over the world a gas content greater than $8 \mathrm{~m}^{3} / t$ is considered enough to initiate an outburst if other conditions are favourable [22] Furthermore, gas content is not fixed and is affected largely by hydrogeologic factors, burial depth, coal metamorphic grade, outcrops, geological structure, etc. [23-27].

\subsection{Gas pressure}

There is a complex relation between gas pressure and outbursts. From Yin's research [28], the increase in gas pressure leads to the increase in porosity of coal seam, then the increase in porosity speed up gas desorption which turns more gas from adsorbed state into free state, resulting in a large volume of free-state gas accumulated and creating a favourable condition for outbursts [29], but it should be noted that here the pressure mainly refers to the low-pressure conditions. Certainly, there is a relationship between gas pressure and gas sorption, which is clearly described in Langmuir adsorption isotherm model back in 1916 [30]. In a research [31] from Poland, using six coal samples selected from the Upper Silesian Coal Basin, an experiment was conducted to describe the adsorption rate of $\mathrm{CH}_{4}$. Under the isothermal conditions a pressure dependence of adsorption rate was clearly observed for the slow sorption processes of $\mathrm{CH}_{4}$, the author found that there is a clear reduction in sorption rate with the increase in pressure. In addition, research [32] also discovered that there exists a gas pressure threshold between 0.5 and 1.0 MPa for outbursts; if the gas pressure is higher than this threshold, the outburst intensity increase with the increase in gas pressure.

\subsection{Gas emission}

Gas emission plays a very important role in outbursts and is directly related to outburst frequency and magnitude [21]. In China, to be more specific to illustrate the gas emission state and the gas content of coal seams, two indexes are generally used: the absolute gas emission rate $Q_{a}\left(\mathrm{~m}^{3} / \mathrm{min}\right)$ and the relative gas emission rate $Q_{r}\left(\mathrm{~m}^{3} / t\right)$. The absolute gas emission rate represents the volumes of gas released per minute, which is obtained through using gas concentration in the vitiated air to multiply the total volumes of the vitiated air (as shown in Equation 1). The relative gas emission rate represents the volumes of gas released per ton of coal yielded, which is obtained using the absolute gas emission rate to divide the coal yield of per minute (as shown in Equation 2).

$$
\begin{aligned}
& Q_{a}=Q \times C \\
& Q_{r}=Q_{a} / A
\end{aligned}
$$


Here, $Q\left(\mathrm{~m}^{3} / \mathrm{min}\right)$ refers to the total volumes of the vitiated air, $C(\%)$ refers to the gas concentration in the vitiated air and $A(t / \mathrm{min})$ denotes the coal yield of per minute.

\subsection{Strength of coal seam}

Coal strength has impact on the outburst occurrence and development. Generally, harder seams have less and smaller fractures, this means that greater amount of energy will be needed to make the fracture propagation happen so that the gas can transport through the coal seam. On the contrary, for softer seams, fractures are easily propagated when in situ stress and gas pressure reach a certain level, which leads to the process of gas transport that are rapidly developed along the entire seam; moreover, abundant pores within the softer seam are more likely to lead to a high gas pressure gradient which acts as a main driving force in gas outburst because the opening and closure of the pores play a great role in affecting gas accumulation and gas pressure. We illustrate this point by taking a mining face as an example: in the process of mining, the mining-induced stresses and the in situ stresses will jointly induce stress concentration to the coal mass near the working face, the stress concentration decreases coal permeability exponentially with the closure of cleats $[33,34]$ and the decreased permeability makes the gas even more difficult to release from the coal mass resulting in high gas pressure and gas accumulation. With the gradient change in the effective stresses (the composition of the mining-induced stresses, the in situ stresses and the pore pressure) in the coal mass, the gradient variation in gas pressure also occurs, which is the formation of the gas pressure gradient. So, for softer coal seam, under the action of effective stresses, pores will be closed and higher gas pressure gradient will be generated.

\subsection{Coal-rank-related aspects}

Coal rank refers to the rank of coal metamorphism. In the process of coalification, under the actions of heat, burial pressure and time, both the physical properties and the chemical composition of the coal present regular changes. Therefore, the degree of metamorphism or coalification generally is obtained by measuring the coal rank indexes such as the volatiles, the vitrinite reflectance, the maceral composition, the carbon content, the hydrogen content, the moisture and the calorific value. Among them the vitrinite reflectance is considered to be the more accurate way in determining the degree of metamorphism because it is not affected by the coal lithotypes, ash content and coal samples. The vitrinite reflectance whose maximum reflectivity is less than $0.5 \%$ is defined as lignite, greater than $2.5 \%$ is defined as anthracite and between them is bituminous coal.

Coal rank impacts on coal and gas outburst not because the degree of coal metamorphism is directly related to the gas content in the coal seam $[35,36]$. Other outburst-related factors such as adsorption capacity [37,38], pore structure [39], porosity [40] and permeability [41] are also related to coal ranks.

\subsection{Geological structures}

Geologic structures are usually the result of the powerful tectonic forces that occur within the earth, which usually include the structures such as faults, folds, fractures and joints, but here we mainly discuss the fault and the fold. For these structures, as can be seen from Shepherd's review [42] and Li's field research in Pingdingshan coalfield [43], most of them are directly associated with outbursts. For the fold, syncline fold is more outburst-prone structure because its compression joints are more favourable to gas storage when compared with tension joints of anticlinal fold. With respect to the fault, different types of faults have significant differences in impact to outbursts. From Lamas research [3], normal faults in many mines have given rise to outbursts because they have a throw greater than the coal seam thickness, which resulted in complete stoppage of gas flow. According to Li's research [44], faults can be divided into open, closed and occluded types. The open type reduces both gas content and methane concentration of nearby coal seams; the closed type leads to the decrease in gas content but the methane concentration is still high; the occluded type results in the development of intensely 
deformed coal and enrichment of coalbed methane in small areas near fault because of fault-sealing properties. In addition, in fault and fold zones, due to many episodes of strong structural deformation, the tectonically deformed coal, which is formed by superimposed reformations from tectonic stress [45], has changed its physical properties such as strength coefficient and rate of gas desorption [46].

\subsection{Hydrogeological conditions}

Both gas and water are fluids coexisted in coal seam, and both their transports and occurrences are associated with porosities of seams, hence the hydrogeological conditions play an important part in outbursts. On one hand, the water seepage in pores directly drives the transport of free-state gas; on the other hand the dissolved gas may also be carried along with the seepage direction. Although there is only $1 \sim 4 \%$ of gas solubility in water, in those areas where the exchanging of groundwater is active the flowing water still can take away a large amount of gas from seams. Besides, water absorbed on the surfaces of pores will reduce the gas adsorption capacity thus in those water-rich areas, the gas content generally gets lower. At present, hydraulic measures such as high-pressure water injection, hydraulic fracturing and hydraulic slotting are often used for releasing seam stresses, increasing permeability and raising moisture. According to previous researches [47-49], the injected water can reduce the outburst disasters by impacting the methane desorption, methane emission and methane diffusion.

\subsection{Stress conditions}

The stresses are the main driving forces of coal and gas outburst, and in underground mining, the stress conditions mainly include two aspects, the in situ stress and the mining-induced stress. The former is mainly related to the geological structures (tectonic stress) and the burial depth (geostatic stress) and the latter is mainly related to the mining conditions such as mining depth, thickness of coal seam, dip angle of coal seam, width of working face etc.

According to the gas outburst accident statistics in China, a high proportion of outburst incidents actually occurred near geological structures, which is because the tectonic stress play a key role in the gas migration and accumulation [3,14,50]. In the process of mining, the variation in mining-induced stresses will affect the opening or closing of the pores and thereby indirectly impacting on the porosity and the permeability of coal. This phenomenon has already been proved by many laboratory tests $[33,34,51]$. In addition, research [52] also found that under the action of stresses, the volumetric shrinkage or swelling of the coal has a significant influence on gas desorption.

\section{Development of an assessment system for outbursts}

\subsection{RES and interaction matrix}

RES introduced firstly by Hudson $[3,53,54]$ is a powerful systematic approach to solve fully coupled problems with all the elements, elements including rock mechanics, engineering parameters, structures, constructions and their interactions. To date, it has already been used all over the world to address a number of engineering projects [55-59].

In RES, the interaction matrix is the basic analytical device and a presentational technique for characterising and linking all associated parameters and interactions between parameters; it was developed from the most simple binary interaction matrix (Figure 1) to the complicated $n \times n$ square matrix. In the interaction matrix for an engineering project (e.g. for an outburst project), the main parameters (or factors) influencing the project are always placed along the leading diagonal (top left to bottom right), called the diagonal terms; and the influence of each individual parameter on any other parameter (also called the interaction between parameters) is generally located in the offdiagonal boxes, and they are named the off-diagonal terms. A project has only two parameters which are the simplest interaction matrix as shown in Figure 1, in this $2 \times 2$ interaction matrix (also named as binary interaction matrix), parameter $A$ and parameter $B$ placed in the leading diagonal are the 


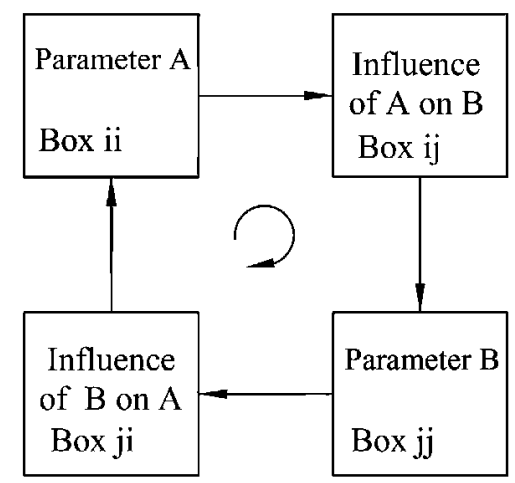

Figure 1. The most simple binary interaction matrix.

main parameters, and the influence of parameter $A$ on parameter $B$ is located in the top right-hand off-diagonal box, the influence of $B$ on $A$ is located in the bottom left-hand off-diagonal box. Of course in real projects, engineering projects with only two parameters are relatively rare, the most common situation is a plurality of parameters may impact the engineering consequence at the same time, thereby in most cases the interaction matrix is a high-order square matrix.

\subsection{Coding approach of interaction matrix}

Once an interaction matrix is established, there are several ways to code it [3], but the most common approach is still the conventional expert semi-quantitative (ESQ) approach. To use the ESQ coding approach, first of all, the off-diagonal terms of the interaction matrix should be assigned corresponding numerical coding values, and such coding values should describe the intensity of the influence of one parameter on the other parameter.

A general illustration of the coding of interaction matrix is shown in Figure 2, as can be seen from the construction of this figure, the row passing through $P i$ indicates the influence of $P i$ on all the other parameters in the system (named as cause terms), while the column through $P i$ represents the influence of the other parameters, i.e. the rest of the system, on $P i$ (named as effect terms). After coding the matrix by inserting the appropriate values for each cause and effect term of the matrix with ESQ approach, the sum of each row and column can be calculated. The sum of a row is termed the 'cause' value and the sum of a column is termed the 'effect' value, designated as coordinates (Cause, Effect) for a particular factor. The 'cause' value $C_{P i}$ represents the way in which $P i$ affects the system; and the 'effect' value $E_{P i}$ represents the effect that the system has on $P i$. The coordinate values for each factor can be plotted in cause and effect space, forming also-called $C-E$ plot [3]. Once the Cause-Effect plot is obtained for a specific project, the assessment or classification system that takes into account all the main parameters and their interactions then can be developed, in the next part, detailed development of an assessment system for outbursts will be given using the above-described approach.

\subsection{Formulating the outburst assessment}

We now return to our problem of developing the outburst assessment system. As we discussed in Section 2, factors including gas content gas pressure, relative gas emission rate, absolute gas emission rate, strength of coal seam, coal-rank-related aspects, geological structures, hydrogeological conditions and stress conditions in varying degrees, they all have impacts on outbursts. So here, these nine parameters involved in outburst are selected as the main parameters to construct the interaction matrix and to establish the assessment system, and the suggested rating values of these nine parameters can be seen in Table 2. According to the constructing principles of interaction matrix described 


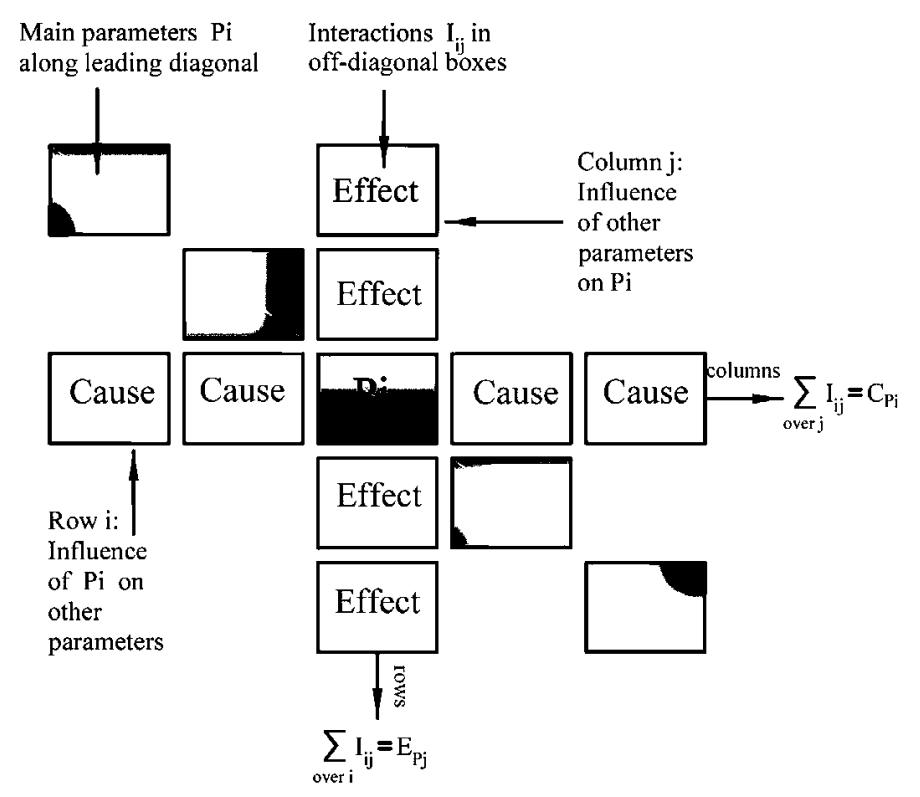

Figure 2. Generation of the cause and effect co-ordinates.

in Section 3.1, the nine main parameters are located along the diagonal elements and the interacting actions between each two parameters are placed in the corresponding off-diagonal elements, thus a $9 \times 9$ square interaction matrix including 9 diagonal terms and 81 off-diagonal terms is constructed (see Figure 3) to represent the outburst system, here the interaction matrix constructing was carried out mainly based upon the knowledge obtained from the previous studies [60-66] and the author's experiences .

For the coding of the established interaction matrix, here we also use the ESQ coding systems suggested by Hudson [3] (see Table 3). In this coding system, the interaction between each two parameters is quantified using numbers from 0 (no interaction) to 4 (critical interaction), numbers 1,2 and 3 represent weak, medium and strong interactions, respectively. Table 4 shows the results of the interaction matrix coding corresponding to Figure 3 using the ESQ coding system. By means on this coding matrix, as described in Section 3.2, the cause value $C$ (the total impact of the parameter on the outburst system) can be obtained as the sum of the off-diagonal rows corresponding to the given parameter, similarly, the effect value $E$ (the total impact of outburst system on a particular parameter) can be obtained as the sum of the off-diagonal columns corresponding to the given parameter. Using a point in a cause-effect coordinate system to represent the cause and effect values corresponding to each parameter, we obtain the $C-E$ plot, which is shown in Figure 4 . Note that in this plot, the parameter interactive intensity $(C+E)$ can be measured along the $C=E$ line and the parameter dominance $(C-E)$ can be measured by the perpendicular distance of the parameter point from this line, the two sets of $45^{\circ}$ lines in the plot indicate contour of equal value for the cause and effect value. So as can be seen from the plot that parameters located in the top right portion of the diagram are more interactive than the parameters located in the bottom left portion, parameters located in the bottom right portion of the diagram are 'dominant' in the system, and the 'subordinate' parameters, they are defined as those which are highly dominated by the system, are located in the top left portion.

The $C-E$ plot is a very helpful tool for understanding the behaviour of each parameter individually as well as studying the whole system, In Figure 4, it can be seen that coal-rank-related aspects (P6) has the most interaction to the outburst system, whereas strength of coal seam (P4) has the least interaction; the plot also shows that geological structures(P7) is the most dominant parameter to the outburst system, and the emission rates (the relative emission rate (P3) and the absolute emission rate(P4)) are 


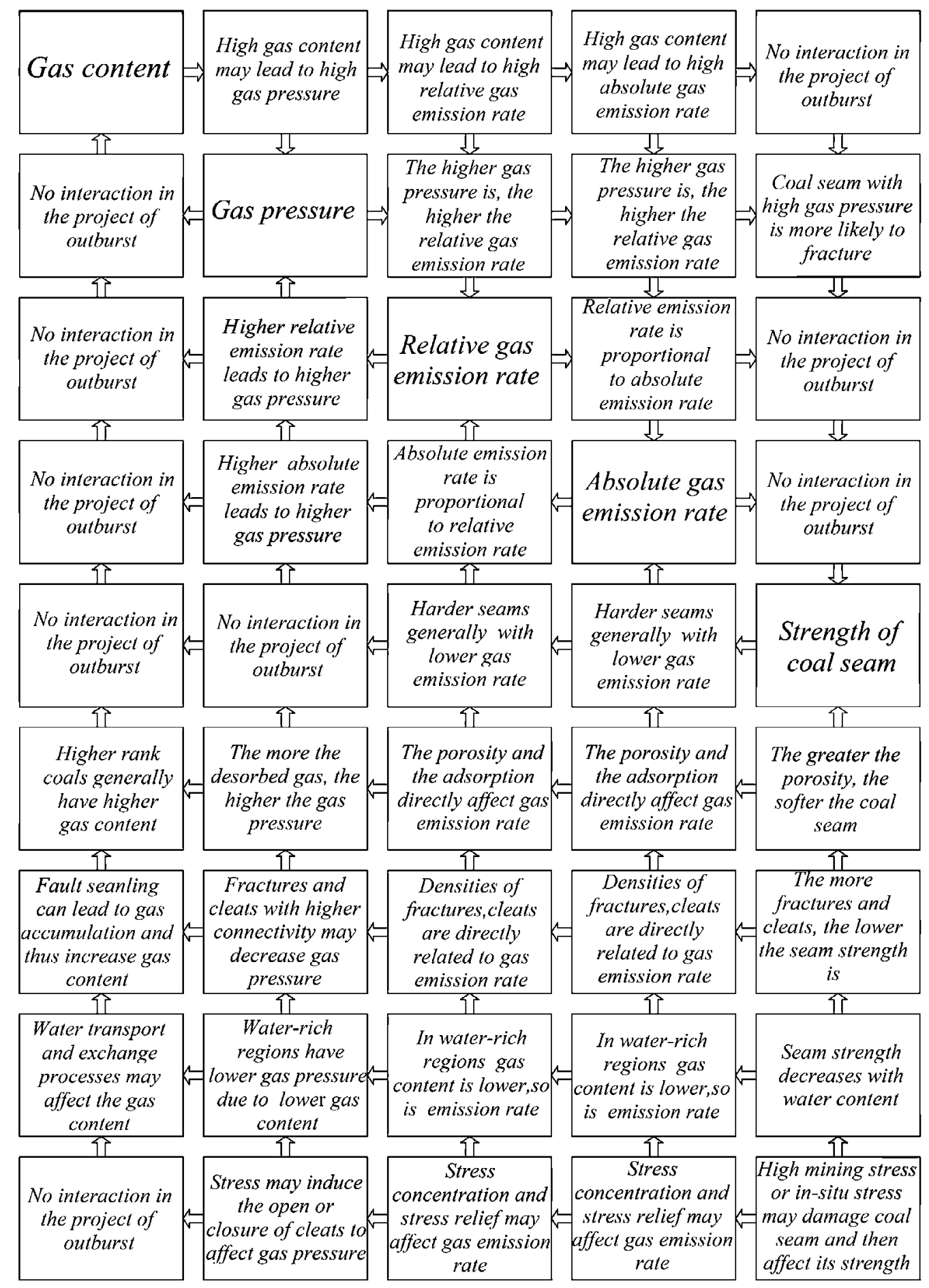

(A)

Figure 3 . The constructed interaction matrix of the coal and gas outburst system.

Note: $A$ is the left part of the matrix and $B$ is the right part of the matrix. 


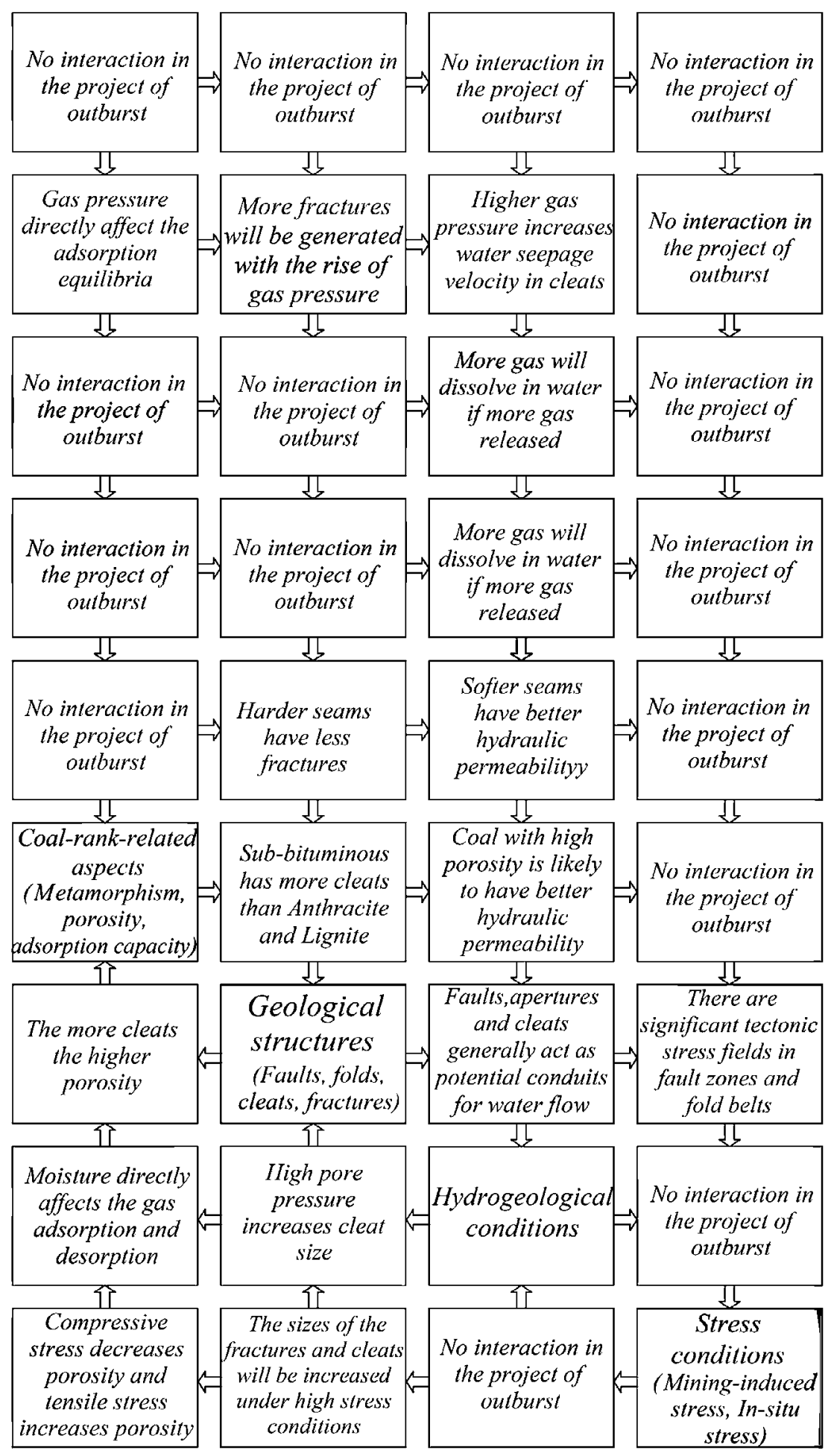

(B)

Figure 3. (Continued). 
Table 2. Suggested rating values of the selected parameters.

\begin{tabular}{|c|c|}
\hline Description & Rating value \\
\hline \multicolumn{2}{|l|}{$\overline{P 1-G a s ~ c o n t e n t}\left(m^{3} / t\right)$} \\
\hline$<5$ & 0 \\
\hline $5-8$ & 1 \\
\hline $8-15$ & 2 \\
\hline$>15$ & 3 \\
\hline \multicolumn{2}{|l|}{ P2-Gas pressure $(\mathrm{MPa})$} \\
\hline$<0.5$ & 0 \\
\hline $0.5-0.74$ & 1 \\
\hline $0.74-1.5$ & 2 \\
\hline$>1.5$ & 3 \\
\hline \multicolumn{2}{|l|}{ P3-Relative gas emission rate $\left(m^{3} / t\right)$} \\
\hline$<5$ & 0 \\
\hline $5-10$ & 1 \\
\hline $10-15$ & 2 \\
\hline$>15$ & 3 \\
\hline \multicolumn{2}{|l|}{ P4-Absolute gas emission rate $\left(\mathrm{m}^{3} / \mathrm{min}\right)$} \\
\hline$<10$ & 0 \\
\hline $10-20$ & 1 \\
\hline $20-40$ & 2 \\
\hline$>40$ & 3 \\
\hline \multicolumn{2}{|l|}{ P5-Strength of coal seam } \\
\hline Hard coal seam (simplified as Hard): $f>3$ & 0 \\
\hline Medium hard coal seam (simplified as Medium): $f \sim 1.5-3$ & 1 \\
\hline Weaker coal seam (simplified as Weaker): f 0.8-1.5 & 2 \\
\hline Soft coal seam (simplified as Soft): $f<0.8$ & 3 \\
\hline \multicolumn{2}{|l|}{ P6-Coal-rank-related aspects } \\
\hline Lignite: low degree of metamorphism, more macropores and less micropores, low adsorption capability & 0 \\
\hline $\begin{array}{l}\text { Sub-bituminous: medium degree of metamorphism, more macropores and more mesopores and less micropo- } \\
\text { res, medium adsorption capability }\end{array}$ & 1 \\
\hline Bituminous: high degree of metamorphism, more micropores and less macropores, high adsorption capability & 2 \\
\hline $\begin{array}{l}\text { Anthracite: very high degree of metamorphism, more micropores and less macropores, very high adsorption } \\
\text { capability }\end{array}$ & 3 \\
\hline \multicolumn{2}{|l|}{ P7-Geological structure } \\
\hline $\begin{array}{l}\text { Simple: small variation on the orientation or attitude of coal seams; small and few faults; low-angle dip of } \\
\text { monoclonal, synclinal or anticlinal structures }\end{array}$ & 0 \\
\hline $\begin{array}{l}\text { Medium: some variations on the orientation or attitude of coal seams; a number of faults; low-angle dip of } \\
\text { monoclonal, synclinal or anticlinal structures; some small-scale folds }\end{array}$ & 1 \\
\hline $\begin{array}{l}\text { Complex: great variation on the orientation or attitude of coal seams; strata are damaged by several major } \\
\text { faults; on the basis of monoclonal, synclinal or anticlinal structures, subordinated folds and faults are further } \\
\text { developed }\end{array}$ & 2 \\
\hline $\begin{array}{l}\text { Very complex: tremendous variation on the orientation or attitude of coal seams; strata are influenced by igne- } \\
\text { ous rocks; high density of faults and folds }\end{array}$ & 3 \\
\hline \multicolumn{2}{|l|}{ P8-Hydrogeological conditions } \\
\hline $\begin{array}{l}\text { Very complex: surrounded by large surface water bodies such as rivers, lakes, reservoirs; a number of large } \\
\text { aquifers; plenty of faults, joints and fractures; water inrush events occurred frequently; with high intensity of } \\
\text { water injection, hydraulic fracturing or hydraulic slotting activities }\end{array}$ & 0 \\
\hline $\begin{array}{l}\text { Complex: with sufficient water supplies from surface water bodies and aquifers; sufficient precipitation; water } \\
\text { inrush events occurred occasionally; with some water injection, hydraulic fracturing or hydraulic slotting } \\
\text { activities }\end{array}$ & 1 \\
\hline $\begin{array}{l}\text { Medium: with some surface water bodies and some aquifers; a number of faults, joints, and fractures; medium } \\
\text { degree of precipitation; without water injection, hydraulic fracturing or hydraulic slotting activities }\end{array}$ & 2 \\
\hline $\begin{array}{l}\text { Simple: away from surface water bodies; no aquifers; potential water conduits such as faults, joints, fractures } \\
\text { are few; located in the region with small precipitation; without water injection, hydraulic fracturing or } \\
\text { hydraulic slotting activities }\end{array}$ & 3 \\
\hline \multicolumn{2}{|l|}{ P9-Stress conditions } \\
\hline $\begin{array}{l}\text { Low: without locating in any fault zones or fold belts; burial depth (mining depth) }<200 \mathrm{~m} \text {; thickness of coal } \\
\text { seam (mining height) }<1.5 \mathrm{~m} \text {; width of working face (mining length) }<100 \mathrm{~m}\end{array}$ & 0 \\
\hline $\begin{array}{l}\text { Medium: without locating in any fault zones or fold belts; burial depth (mining depth) }-200 \sim 600 \mathrm{~m} \text {; thickness } \\
\text { of coal seam (mining height) }-1.5 \sim 3.5 \mathrm{~m} \text {; width of working face (mining length) }-100 \sim 200 \mathrm{~m}\end{array}$ & 1 \\
\hline $\begin{array}{l}\text { High: located in fault zones or fold belts with low tectonic stress fields; burial depth (mining depth) - } \\
600 \sim 800 \mathrm{~m} \text {; thickness of coal seam (mining height) }-3.5 \sim 8 \mathrm{~m} \text {; width of working face (mining length) } \\
-200 \sim 300 \mathrm{~m}\end{array}$ & 2 \\
\hline $\begin{array}{l}\text { Very high: located in fault zones or fold belts with strong tectonic stress fields; burial depth (mining depth) } \\
>800 \mathrm{~m} \text {; thickness of coal seam (mining height) }>8 \mathrm{~m} \text {; width of working face (mining length) }>300 \mathrm{~m}\end{array}$ & 3 \\
\hline
\end{tabular}


Table 3. ESQ coding value suggested by Hudson [20].

\begin{tabular}{lc}
\hline Significance & Coding value \\
\hline No interaction & 0 \\
Weak interaction & 1 \\
Medium interaction & 2 \\
Strong interaction & 3 \\
Critical interaction & 4 \\
\hline
\end{tabular}

Table 4. The results of the interaction matrix coding corresponding to Figure 3 using the ESQ coding system.

\begin{tabular}{|c|c|c|c|c|c|c|c|c|c|c|}
\hline \multirow[b]{2}{*}{$\overline{\mathrm{P} 1}$} & \multirow[b]{2}{*}{4} & \multicolumn{9}{|c|}{ Interaction matrix coding } \\
\hline & & 4 & 4 & 0 & 0 & 0 & 0 & 0 & 12 & Cause \\
\hline 0 & P2 & 4 & 4 & 2 & 3 & 2 & 2 & 0 & 17 & values \\
\hline 0 & 4 & P3 & 4 & 0 & 0 & 0 & 1 & 0 & 9 & \\
\hline 0 & 4 & 4 & P4 & 0 & 0 & 0 & 1 & 0 & 9 & \\
\hline 0 & 0 & 2 & 2 & P5 & 0 & 2 & 2 & 0 & 8 & \\
\hline 4 & 3 & 4 & 4 & 3 & P6 & 2 & 3 & 0 & 23 & \\
\hline 4 & 2 & 3 & 3 & 3 & 3 & P7 & 3 & 4 & 25 & \\
\hline 3 & 3 & 3 & 3 & 2 & 4 & 1 & P8 & 0 & 19 & \\
\hline 0 & 4 & 3 & 3 & 4 & 3 & 2 & 0 & P9 & 19 & \\
\hline 11 & 24 & 27 & 27 & $\begin{array}{c}14 \\
\text { Effect values }\end{array}$ & 13 & 9 & 12 & 4 & $\begin{array}{l}\sum_{i} C=141 \\
\sum_{i} E=141\end{array}$ & \\
\hline
\end{tabular}

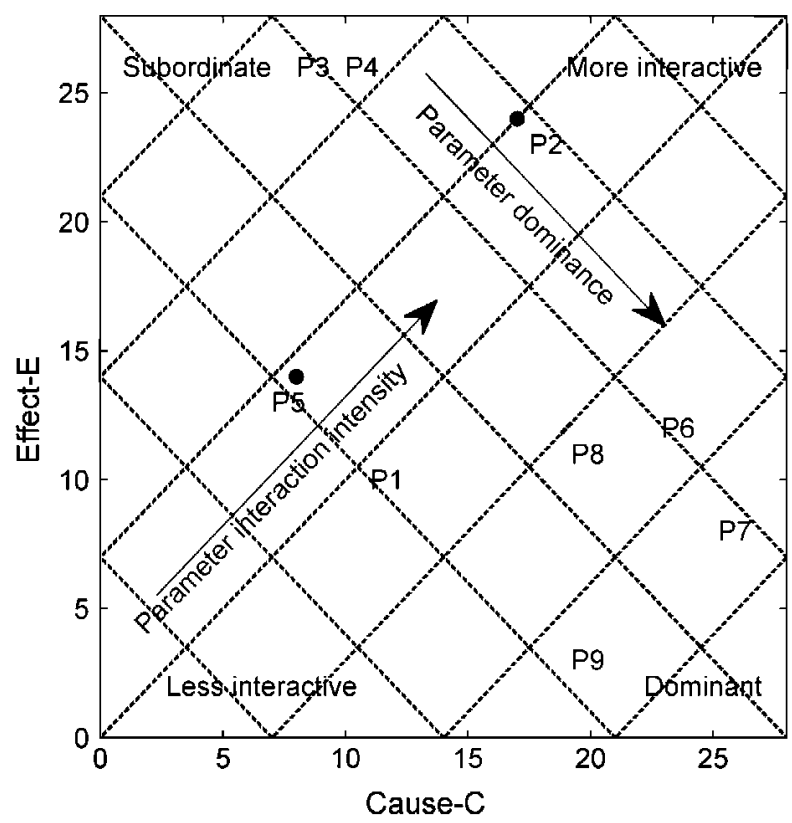

Figure 4. Parameter interaction intensity and dominance.

the subordinate parameters, this means that the emission rates are the parameters which are highly influenced by other parameters in the outburst system.

In addition, the parameter interactive intensity $(C+E)$ also can be used to identify the level of interactivity of the parameters, the greater the parameter interactive intensity, the greater the impact of the parameter on the system. In Figure 5, the histogram of parameter interactive intensity corresponding 


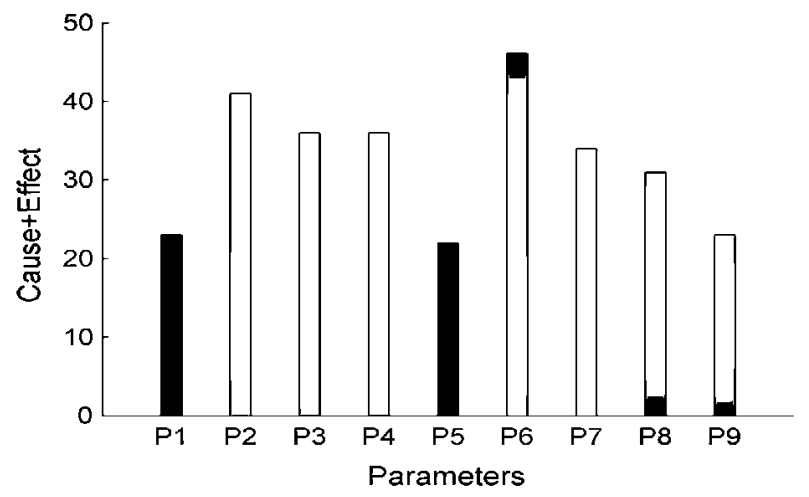

Figure 5. The histogram of parameter interactive intensity.

Table 5. The weighted coefficients of the selected parameters.

\begin{tabular}{lrrrrc}
\hline Parameters & $C_{i}$ & $E_{i}$ & $C_{i}+E_{i}$ & $w_{i}$ & $s_{i}$ \\
\hline Gas content (P1) & 12 & 11 & 23 & 8.156 & 2.719 \\
Gas pressure (P2) & 17 & 24 & 41 & 14.539 & 4.846 \\
Relative gas emission rate (P3) & 9 & 27 & 36 & 12.766 & 4.255 \\
Absolute gas emission rate (P4) & 9 & 27 & 36 & 12.766 & 4.255 \\
Strength of coal seam (P5) & 8 & 14 & 22 & 7.801 & 2.600 \\
Coal-rank-related aspects (P6) & 23 & 13 & 46 & 12.766 & 4.255 \\
Geological structures (P7) & 25 & 9 & 34 & 12.057 & 4.019 \\
Hydrogeological conditions (P8) & 19 & 12 & 31 & 10.993 & 3.664 \\
Stress conditions (P9) & 19 & 4 & 23 & 8.156 & 2.719 \\
\hline
\end{tabular}

to parameters considered in the outburst system is shown. For the propose of further developing an outburst assessment system, we transform these $C+E$ values into a percentage form (w) acting as weighting coefficients(see Equation 3), which express the proportional share of each parameter (as an outburst causing factor) in outburst system.

$$
w_{i}=\frac{C_{i}+E_{i}}{\sum_{i=1}^{n}\left(C_{i}+E_{i}\right)}
$$

Where $C_{i}$ is cause value of the $i$-th parameter; $E_{i}$ is the effect value of the $i$-th parameter; $i$ denotes the number of parameter and $n$ refers to the total number of selected parameters.

The next step is to compute the outburst index $(I)$, which can be calculated by using the following equation.

$$
I=\sum_{i=1}^{n} s_{i} p_{i}
$$

Where $p_{i}$ is the rating value of the $i$-th parameter (see Table 2); and $s_{i}$ is the normalized weighting coefficients of the $i$-th parameter in the outburst system, which is obtained by using $w_{i}$ to divide with the maximum rating value (See Equation 5 ). How to convert $C+E$ to weighting coefficients by using Equations 3 and 5 are given in detail in Table 5.

$$
s_{i}=\frac{w_{i}}{3}
$$


Table 6. Parameter value of the 11 mines which have high-risk of outburst (11 mines described in Table 1).

\begin{tabular}{|c|c|c|c|c|c|c|c|c|c|}
\hline Mines & P1 & $\mathrm{P} 2$ & P3 & P4 & P5 & P6 & P7 & P8 & P9 \\
\hline Daping coal mine & 16.40 & 1.23 & 10.44 & 19.55 & Medium & Anthracite & Complex & Medium & Very high \\
\hline Jiulishan coal mine & $>15.15$ & 2.08 & 24.17 & 48.57 & Hard & Anthracite & Very complex & Complex & High \\
\hline Yongshan coal mine & 25.17 & 1.0 & 45.02 & 14.91 & Weaker & Anthracite & Medium & Very complex & Medium \\
\hline Houxi coal mine & 12.65 & 2.3 & 40.69 & 2.71 & Hard & Bituminous & Complex & Very complex & High \\
\hline $\begin{array}{l}\text { Sangshuping coal } \\
\text { mine }\end{array}$ & 11.36 & 1.5 & 15.29 & 62.27 & Soft & Anthracite & Simple & Very complex & Medium \\
\hline Tonghua coal mine & $>18.21$ & 2.4 & 77.51 & 49.09 & Soft & Anthracite & Complex & Very complex & Low \\
\hline Zhengzhong coal mine & 15.49 & 0.76 & 83.82 & 1.66 & Soft & Anthracite & Medium & Simple & Medium \\
\hline Xinxing coal mine & $4.85-8.7$ & 1.1 & 20.49 & 65.57 & Soft & Bituminous & Medium & Medium & High \\
\hline Qujiang coal mine & 9.0 & 6.0 & 32.29 & 58.85 & Soft & Bituminous & Simple & Complex & Very high \\
\hline Yushe coal mine & 13.94 & 1.52 & 13.94 & 20.61 & Weaker & Anthracite & Medium & Medium & Medium \\
\hline Xintian coal mine & 20.59 & 2.32 & 43.65 & 47.62 & Weaker & Anthracite & Medium & Simple & Medium \\
\hline
\end{tabular}


Table 7. The assessment results of the 11 mines corresponding to Table 6.

\begin{tabular}{|c|c|c|c|c|c|c|c|c|c|c|}
\hline \multirow[b]{2}{*}{ Mines } & \multicolumn{9}{|c|}{ Parameter rating value } & \multirow{2}{*}{$\begin{array}{l}\text { Comprehensive } \\
\text { outburst index }\end{array}$} \\
\hline & P1 & P2 & P3 & P4 & P5 & P6 & P7 & P8 & P9 & \\
\hline Daping coal mine & 3 & 2 & 2 & 1 & 3 & 2 & 2 & 2 & 3 & 70.45 \\
\hline Jiulishan coal mine & 3 & 3 & 3 & 3 & 3 & 1 & 3 & 1 & 2 & 81.44 \\
\hline Yongshan coal mine & 3 & 2 & 3 & 1 & 3 & 1 & 1 & 0 & 1 & 53.66 \\
\hline Houxi coal mine & 2 & 3 & 3 & 0 & 2 & 1 & 2 & 0 & 2 & 55.67 \\
\hline $\begin{array}{l}\text { Sangshuping coal } \\
\text { mine }\end{array}$ & 2 & 2 & 3 & 3 & 3 & 1 & 0 & 0 & 1 & 55.43 \\
\hline Tonghua coal mine & 3 & 3 & 3 & 3 & 3 & 0 & 2 & 0 & 0 & 64.06 \\
\hline $\begin{array}{l}\text { Zhengzhong coal } \\
\text { mine }\end{array}$ & 3 & 2 & 3 & 0 & 3 & 0 & 1 & 3 & 1 & 56.14 \\
\hline Xinxing coal mine & 1 & 2 & 3 & 3 & 2 & 1 & 1 & 2 & 2 & 64.18 \\
\hline Qujiang coal mine & 2 & 3 & 3 & 3 & 2 & 3 & 0 & 1 & 3 & 75.29 \\
\hline Yushe coal mine & 2 & 3 & 2 & 2 & 3 & 1 & 1 & 2 & 1 & 63.12 \\
\hline Xintian coal mine & 3 & 3 & 3 & 3 & 3 & 1 & 1 & 3 & 1 & 78.01 \\
\hline $\begin{array}{l}\text { Maximum rating } \\
\text { value } p_{i}\end{array}$ & 3 & 3 & 3 & 3 & 3 & 3 & 3 & 3 & 3 & 100 \\
\hline $\begin{array}{l}\text { Weighted coeffi- } \\
\text { cients } s_{i}\end{array}$ & 2.719 & 4.846 & 4.255 & 4.255 & 2.60 & 4.255 & 4.019 & 3.664 & 2.719 & \\
\hline
\end{tabular}

\section{Case studies and discussions}

Now we return to the outburst mines we mentioned in Section 1 (Table 1) (hereinafter these 11 mines are referred to as the accident group), corresponding to the parameters described in Table 2 , here we further list more detailed information of these mines (see Table 6). Just as the same as the front sections, in this section, $\mathrm{P} 1\left(\mathrm{~m}^{3} / t\right)$ refers to gas content, $\mathrm{P} 2$ (MPa) refers to gas pressure, $\mathrm{P} 3\left(\mathrm{~m}^{3} / t\right)$ refers to relative gas emission rate, $\mathrm{P} 4\left(\mathrm{~m}^{3} / \mathrm{min}\right)$ refers to absolute gas emission rate, $\mathrm{P} 5$ refers to strength of coal seam, P6 represents coal-rank-related aspects, P7 refers to geological structure, P8 denotes hydrogeological condition and P9 denotes stress condition.

With the above developed assessment approach, we now calculate the comprehensive outburst index to each mine of the accident group. The calculation process consists of two main steps: the first step is to rate each corresponding parameter according to Table 2, it should be emphasised here that in this paper, we apply 'majority rule' to rate those non-numerical parameters (geological structure, hydrogeological condition and stress condition). For example, if a $3.9 \mathrm{~m}$ coal seam is located in a fault zone with low tectonic stress fields and has burial depth at $750 \mathrm{~m}$, we rate this seam as a high stress case because it satisfies the majority conditions of high stress (satisfy 3 of 4 as can be seen in Table 2). After finishing the first step, together with the normalised weighting coefficients obtained in Table 5 the comprehensive outburst index thereby can be calculated by using Equation 4.

In Table 7, the assessment results of the accident group are given, as can be seen from Table 7 that all the 11 mines have comprehensive outburst indexes greater than 50, indicating that all of them are high-potential outburst mines. Since in fact gas accident disasters have already occurred in these 11 mines in the past few years, so in actual situations these mines are serious outburst mines, in this sense, our evaluation results actually are consistent with the actual situations.

In Tables 8 and 9, more typical coal mines are introduced to assess their comprehensive outburst indexes. In Table 8 we introduce 10 typical risk-free outburst mines (hereinafter these 10 mines are referred to as the risk-free group) selected from Xinjiang Uygur Autonomous Region (Tunbao coal mine, Wudong coal mine, Jiangou coal mine, Kuangou coal mine), Inner Mongolia Autonomous Region (Gubulianta coal mine, Shigetai coal mine, Sidaoliu coal mine), Jiangsu Province (Chacheng coal mine), Shanxi Province (Liulin coal mine, Tongjialiang coal mine), these 10 mines are located in the regions with low gas content and they never had outburst records in their history of coal production. In Table 9, we introduce 18 coal mines selected from Huainan Mining Group (the first 11 mines of Table 9) and Pingdingshan Coal Group (the last 7 mines of Table 9), the former is located in Anhui 
Table 8. Parameter value of the 10 mines which are risk-free in outburst.

\begin{tabular}{|c|c|c|c|c|c|c|c|c|c|}
\hline Mines & P1 & $\mathrm{P} 2$ & P3 & P4 & P5 & P6 & P7 & P8 & P9 \\
\hline Tunbao coal mine & 1.34 & $0.2-0.75$ & 2.07 & 6.76 & Hard & Sub-bituminous & Simple & Simple & Low \\
\hline Wudong coal mine & 2.39 & $0.26-0.55$ & 5.78 & 15.8887 & Weaker & Sub-bituminous & Simple complex & Simple & Very high \\
\hline Jiangou coal mine & 0.19 & $0.3-0.65$ & 2.34 & 11.908 & Medium & Sub-bituminous & Medium & Simple & Very high \\
\hline Kuangou coal mine & 0.284 & $<0.5$ & 2.63 & 5.69 & Hard & Sub-bituminous & Simple & Simple & Very high \\
\hline Gubulianta coal mine & 0.19 & $<0.5$ & 0.09 & 4.42 & Weaker & Sub-bituminous & Simple & Medium & Low \\
\hline Shigetai coal mine & 0.78 & $0.11-0.62$ & 0.13 & 2.80 & Hard & Sub-bituminous & Medium & Complex & Low \\
\hline Sidaoliu coal mine & $<1$ & $0.31-0.56$ & 0.27 & 0.92 & Medium & Sub-bituminous & Simple & Simple & Low \\
\hline Chacheng coal mine & 2.35 & $<0.5$ & 2.81 & 5.35 & Hard & Bituminous & Simple & Simple & High \\
\hline Liulin coal mine & 9.02 & $0.38-0.52$ & 7.74 & 9.67 & Hard & Bituminous & Simple & Medium & Medium \\
\hline Tongjialiang coal mine & 0.46 & $<0.74$ & 1.53 & 4.45 & Soft & Bituminous & Complex & Medium & Medium \\
\hline
\end{tabular}

Table 9. Parameter value of the 18 mines selected from Huainan Mining Group and Pingdingshan Coal Group.

\begin{tabular}{|c|c|c|c|c|c|c|c|c|c|}
\hline Mines & P1 & $\mathrm{P} 2$ & P3 & P4 & P5 & P6 & P7 & P8 & P9 \\
\hline Lizuizi coal mine & 7.13 & 1.8 & 8.9 & 16.80 & Soft & Bituminous & Medium & Very complex & High \\
\hline Xieyi coal mine & 18 & 3.4 & 19.5 & 66.0 & Soft & Bituminous & Very complex & Complex & Very High \\
\hline Xie'er coal mine & 10.46 & 3.5 & 30.13 & 60.37 & Soft & Bituminous & Very complex & Complex & Very High \\
\hline Xinzhuangzi coal mine & 19 & 2.9 & 22.8 & 116.6 & Soft & Bituminous & Complex & Complex & High \\
\hline Panyi coal mine & 22 & 2.4 & 22.4 & 113.0 & Soft & Bituminous & Very complex & Complex & Very High \\
\hline Pansan coal mine & 21 & 2.5 & 15.12 & 63.11 & Soft & Bituminous & Complex & Complex & Very High \\
\hline Zhangji coal mine & 17.27 & 1.7 & 8.7 & 105.14 & Soft & Bituminous & Complex & Complex & High \\
\hline Xieqiao coal mine & 8.0 & 2.55 & 3.2 & 50.0 & Weaker & Bituminous & Medium & Complex & High \\
\hline Dingji coal mine & 6.9 & 1.3 & 7.57 & 77.83 & Weaker & Bituminous & Complex & Complex & Very High \\
\hline Guqiao coal mine & 8.2 & 3.2 & 4.2 & 37.0 & Soft & Bituminous & Medium & Simple & Very High \\
\hline Zhuji coal mine & 8.08 & 3.2 & 32.26 & 153.42 & Soft & Bituminous & Complex & Complex & High \\
\hline Pingdingshan No.1 & 6.21 & 1.75 & 6.68 & 39.18 & Soft & Bituminous & Complex & Simple & High \\
\hline Pingdingshan No.2 & 8.26 & 1.23 & 3.45 & 21.5 & Soft & Bituminous & Medium & Medium & High \\
\hline Pingdingshan No.4 & 7.14 & 1.1 & 9.97 & 53.07 & Soft & Bituminous & Complex & Simple & High \\
\hline Pingdingshan No.5 & 19.5 & 1.85 & 13.1 & 40.026 & Soft & Bituminous & Complex & Simple & High \\
\hline Pingdingshan No.8 & 16.9 & 1.8 & 20.74 & 24.91 & Soft & Bituminous & Complex & Simple & High \\
\hline Pingdingshan No.10 & 18 & 2.0 & 21.96 & 100.86 & Soft & Bituminous & Complex & Simple & High \\
\hline Pingdingshan No.12 & 18.35 & 2.6 & 14.45 & 42.7 & Soft & Bituminous & Complex & Medium & Very High \\
\hline
\end{tabular}


Province in southern China and the latter is located in Henan Province in northern China, both of them are considered to be the most typical outburst mining regions in China.

The final assessment results of the risk-free group are shown in Table 10. As can be seen in this table, except one of them has a comprehensive outburst index greater than 30, both of the other 9 mines have a low comprehensive outburst index less than 30 . This is why these mines never had outburst problems in their history of production. The final assessment results of the high risk group are given in Table 11, as shown in the table all of these mines have comprehensive outburst indexes greater than 50 and several of them even exceed 80, so our assessment results also suggest that these mines are of high-risk outburst mines.

From the calculating results of the above three groups of mines, we can see that out assessment results in fact are fully consistent with the actual situations. The accident group, 11 mines of having outburst accidents in the past few years, evaluating results show that all of their comprehensive outburst indexes greater than 50; the risk-free group, 10 mines selected from the regions with low risk of outburst, assessing results show that almost all of their comprehensive outburst indexes less than 30; the high-risk group, 18 mines selected from the most typical outburst mining regions, evaluating results also show that all of their comprehensive outburst indexes greater than 50 . So the three groups of the case studies suggest that our assessment results are fully consistent with the actuations the quantitative assessment approach we developed in this study is reliable.

It should be pointed out that although each comprehensive outburst index calculated in the above contents represents the overall gas outburst risk level to a whole mine, it never implies that throughout a whole mine the gas outburst risks are always the same. In actually situations, even in a same mine with the same coal rank, the similar coal strength, the similar geological structure and the similar hydrological condition, the outburst risks also can be totally different in different mining areas because the gas contents, gas pressure and gas emission rate are generally different in different coal seams and the mining-induced stresses are also different in different working faces.

In order to better illustrate the points of the preceding paragraph, five working faces in the same mine (Zhangji coal mine in Huainan Mining Group) were introduced to assess their outburst indexes. Assuming that the five working faces have the same coal rank, the similar coal strength, the similar geological structure and the similar hydrological conditions (the rating value of these parameters can be found in Table 11), together with the other corresponding related parameter values listed in Table 12 we obtain the assessment result of the five working faces as shown in Table 13, as can be seen in Table 13, in the same mine, for different mining faces, their outburst indexes are totally different, the lowest can be as low as 30.731 and the highest may reach as high as 71.391. Therefore,

Table 10. The assessment results of the 10 mines corresponding to Table 8 .

\begin{tabular}{|c|c|c|c|c|c|c|c|c|c|c|}
\hline \multirow[b]{2}{*}{ Mines } & \multicolumn{9}{|c|}{ Parameter rating value } & \multirow{2}{*}{$\begin{array}{l}\text { Comprehensive } \\
\text { outburst index }\end{array}$} \\
\hline & P1 & $\mathrm{P} 2$ & P3 & P4 & P5 & P6 & P7 & P8 & P9 & \\
\hline Tunbao coal mine & 0 & 1 & 0 & 0 & 0 & 1 & 0 & 0 & 0 & 9.101 \\
\hline Wudong coal mine & 0 & 0 & 1 & 1 & 2 & 1 & 0 & 0 & 3 & 26.12 \\
\hline Jiangou coal mine & 0 & 1 & 0 & 1 & 1 & 1 & 1 & 0 & 3 & 28.13 \\
\hline Kuangou coal mine & 0 & 0 & 0 & 0 & 0 & 1 & 0 & 0 & 3 & 12.41 \\
\hline Gubulianta coal mine & 0 & 0 & 0 & 0 & 2 & 1 & 0 & 1 & 0 & 13.12 \\
\hline Shigetai coal mine & 0 & 1 & 0 & 0 & 0 & 1 & 1 & 2 & 0 & 20.45 \\
\hline Sidaoliu coal mine & 0 & 0 & 0 & 0 & 1 & 1 & 0 & 0 & 0 & 6.86 \\
\hline Chacheng coal mine & 0 & 0 & 0 & 0 & 0 & 2 & 0 & 0 & 2 & 13.95 \\
\hline Liulin coal mine & 1 & 0 & 1 & 0 & 0 & 2 & 0 & 1 & 1 & 21.87 \\
\hline $\begin{array}{l}\text { Tongjialiang coal } \\
\text { mine }\end{array}$ & 0 & 1 & 0 & 0 & 3 & 2 & 2 & 1 & 1 & 35.58 \\
\hline $\begin{array}{l}\text { Maximum rating } \\
\text { value } p\end{array}$ & 3 & 3 & 3 & 3 & 3 & 3 & 3 & 3 & 3 & 100 \\
\hline $\begin{array}{l}\text { Weighted coeffi- } \\
\text { cients } s_{i}\end{array}$ & 2.719 & 4.846 & 4.255 & 4.255 & 2.60 & 4.255 & 4.019 & 3.664 & 2.719 & \\
\hline
\end{tabular}


Table 11. The assessment results of the 18 mines corresponding to Table 9.

\begin{tabular}{|c|c|c|c|c|c|c|c|c|c|c|}
\hline \multirow[b]{2}{*}{ Mines } & \multicolumn{9}{|c|}{ Parameter rating value } & \multirow{2}{*}{$\begin{array}{l}\text { Comprehensive } \\
\text { outburst index }\end{array}$} \\
\hline & $\mathrm{P} 1$ & $\mathrm{P} 2$ & P3 & P4 & P5 & P6 & P7 & P8 & P9 & \\
\hline Lizuizi coal mine & 1 & 3 & 1 & 1 & 3 & 2 & 1 & 0 & 2 & 51.53 \\
\hline Xieyi coal mine & 3 & 3 & 3 & 3 & 3 & 2 & 3 & 1 & 3 & 88.41 \\
\hline Xie'er coal mine & 2 & 3 & 3 & 3 & 3 & 2 & 3 & 1 & 3 & 85.69 \\
\hline $\begin{array}{l}\text { Xinzhuangzi coal } \\
\text { mine }\end{array}$ & 3 & 3 & 3 & 3 & 3 & 2 & 2 & 1 & 2 & 81.67 \\
\hline Panyi coal mine & 3 & 3 & 3 & 3 & 3 & 2 & 3 & 1 & 3 & 88.41 \\
\hline Pansan coal mine & 3 & 3 & 3 & 3 & 3 & 2 & 2 & 1 & 3 & 84.39 \\
\hline Zhangji coal mine & 3 & 3 & 1 & 3 & 3 & 2 & 2 & 1 & 2 & 73.10 \\
\hline Xieqiao coal mine & 2 & 3 & 0 & 3 & 2 & 2 & 1 & 1 & 2 & 59.57 \\
\hline Dingji coal mine & 1 & 2 & 1 & 3 & 2 & 2 & 2 & 1 & 3 & 63.0 \\
\hline Guqiao coal mine & 2 & 3 & 0 & 2 & 3 & 2 & 1 & 3 & 3 & 67.96 \\
\hline Zhuji coal mine & 2 & 3 & 3 & 3 & 3 & 2 & 2 & 1 & 2 & 78.96 \\
\hline Pingdingshan No.1 & 1 & 3 & 1 & 3 & 3 & 2 & 2 & 3 & 2 & 75.06 \\
\hline Pingdingshan No.2 & 2 & 2 & 0 & 2 & 3 & 2 & 1 & 2 & 2 & 56.74 \\
\hline Pingdingshan No.4 & 1 & 2 & 2 & 3 & 3 & 2 & 2 & 3 & 2 & 74.46 \\
\hline Pingdingshan No.5 & 3 & 3 & 2 & 3 & 3 & 2 & 2 & 3 & 2 & 84.75 \\
\hline Pingdingshan No.8 & 3 & 3 & 3 & 2 & 3 & 2 & 2 & 3 & 2 & 84.75 \\
\hline Pingdingshan No.10 & 3 & 3 & 3 & 3 & 3 & 2 & 2 & 3 & 2 & 89.0 \\
\hline Pingdingshan No.12 & 3 & 3 & 2 & 3 & 3 & 2 & 2 & 2 & 3 & 83.8 \\
\hline $\begin{array}{l}\text { Maximum rating } \\
\text { value } p_{i}\end{array}$ & 3 & 3 & 3 & 3 & 3 & 3 & 3 & 3 & 3 & 100 \\
\hline $\begin{array}{l}\text { Weighted coeffi- } \\
\text { cients } s_{i}\end{array}$ & 2.719 & 4.846 & 4.255 & 4.255 & 2.60 & 4.255 & 4.019 & 3.664 & 2.719 & \\
\hline
\end{tabular}

Table 12. Parameter value of the 5 working faces selected from Zhangji coal mine.

\begin{tabular}{|c|c|c|c|c|c|c|c|}
\hline $\begin{array}{l}\text { Working } \\
\text { faces }\end{array}$ & Gas content & $\begin{array}{l}\text { Gas pres- } \\
\text { sure }\end{array}$ & $\begin{array}{c}\text { Relative gas } \\
\text { emission } \\
\text { rate }\end{array}$ & $\begin{array}{c}\text { Absolute } \\
\text { gas emis- } \\
\text { sion rate }\end{array}$ & $\begin{array}{c}\text { Mining } \\
\text { depth (m) }\end{array}$ & $\begin{array}{l}\text { Length of } \\
\text { working } \\
\text { face }(\mathrm{m})\end{array}$ & $\begin{array}{l}\text { Height } \\
\text { of coal } \\
\text { seam(m) }\end{array}$ \\
\hline $\begin{array}{l}\text { Working face } \\
1122\end{array}$ & 9.14 & 1.7 & 5.1 & 24.09 & $-409 \sim-560$ & 200 & 3.6 \\
\hline $\begin{array}{l}\text { Working face } \\
1112\end{array}$ & 7.21 & 0.9 & 12.2 & 36.22 & $-578 \sim-633$ & 240 & 2.81 \\
\hline $\begin{array}{l}\text { Working face } \\
1222\end{array}$ & 6.81 & 1.2 & 16.2 & 50.46 & $-578 \sim-610$ & 200 & 3.8 \\
\hline $\begin{array}{l}\text { Working face } \\
1215\end{array}$ & 6.69 & 0.94 & 5.0 & 24.09 & $-409 \sim-560$ & 200 & 3.6 \\
\hline $\begin{array}{l}\text { Working face } \\
1411\end{array}$ & 2.92 & 0.21 & 0.85 & 3.92 & $-418 \sim-483$ & 240 & 2.6 \\
\hline
\end{tabular}

for using our developed approach, under different mining conditions, the assessment results will be totally different.

Based on the above case studies (the three groups of mines and the five working faces), when using our approach, we suggest to use the following criteria as the evaluation standard to assess the outburst risk:

Outburst $<30 \quad$ Risk free in outburst;

$30 \leq$ Outburst $<50 \quad$ Medium risk in outburst;

$50 \leq$ Outburst $<80 \quad$ High risk in outburst;

$80 \leq$ Outburst Extreme risk in outburst.

In actual mining practices, the corresponding measures should also be taken to control the outburst hazards based on the risk degree. For the medium risk in outburst, the strict gas monitoring and the high level of mine ventilation management are very necessary. For the high risk or the extreme risk in outburst, simply improving mine ventilation and strengthening gas monitoring are not enough, 
Table 13. The assessment results of the 5 working faces corresponding to Table 12.

\begin{tabular}{|c|c|c|c|c|c|c|c|c|c|c|}
\hline \multirow[b]{2}{*}{ Working faces } & \multicolumn{9}{|c|}{ Parameter rating value } & \multirow{2}{*}{$\begin{array}{l}\text { Comprehensive } \\
\text { outburst index }\end{array}$} \\
\hline & P1 & $\mathrm{P} 2$ & P3 & P4 & P5 & P6 & P7 & P8 & P9 & \\
\hline Working face 1122 & 2 & 3 & 1 & 2 & 3 & 2 & 2 & 1 & 1 & 63.472 \\
\hline Working face 1112 & 1 & 2 & 2 & 2 & 3 & 2 & 2 & 1 & 2 & 62.881 \\
\hline Working face 1222 & 1 & 2 & 3 & 3 & 3 & 2 & 2 & 1 & 2 & 71.391 \\
\hline Working face 1215 & 1 & 2 & 0 & 2 & 3 & 2 & 2 & 1 & 1 & 51.652 \\
\hline Working face 1411 & 0 & 0 & 0 & 0 & 3 & 2 & 2 & 1 & 1 & 30.731 \\
\hline $\begin{array}{l}\text { Maximum rating } \\
\text { value } p_{i}\end{array}$ & 3 & 3 & 3 & 3 & 3 & 3 & 3 & 3 & 3 & 100 \\
\hline $\begin{array}{l}\text { Weighted coeffi- } \\
\text { cients } s_{i}\end{array}$ & 2.719 & 4.846 & 4.255 & 4.255 & 2.60 & 4.255 & 4.019 & 3.664 & 2.719 & \\
\hline
\end{tabular}

more complicated measures such as gas drainage [67-69], hydraulic slotting [70,71], mining protective seam $[72,73]$, etc. should be should be taken to prevent outburst accidents.

\section{Conclusions}

In this paper, a new quantitative assessment approach based on the RES was developed to assess the outburst risk of coal mine. We selected the gas content, gas pressure, the relative gas emission rate, the absolute emission rate, the strength of coal seam, the coal-rank-related aspects, the geological structure, the hydrogeological condition and the stress condition as the nine main parameters to construct the interaction matrix, through the coding of the matrix, we found that coal-rank-related aspects is the most interactive parameter and has the most impact on outburst, the geological structures has the most dominance on the outburst system and the relative and absolute gas emission rates are two of the parameters which are highly influenced by other parameters.

Based on the coding of the interaction matrix we also obtained the weighted coefficients for each parameter, these weighted coefficients together with the rating value associated with each parameter were applied to develop an comprehensive outburst index which ranges between 0 and 100. In addition, three groups of coal mine selected from China were used for conducting the case studies with the developed approach, the assessment results were fully consistent with the actual situations, this indicates that the new developed approach is applicable and can be recommended to apply in practical mining engineering.

\section{Acknowledgments}

The authors would like to thank the China Scholarship Council (CSC) for financial supports and also thanks to Dr. Zhang for helping in collecting data.

\section{Disclosure statement}

No potential conflict of interest was reported by the authors.

\section{Funding}

This work was supported by the China Scholarship Council.

\section{References}

[1] S. Xue, L. Yuan, Y. Wang, and J. Xie, Numerical analyses of the major parameters affecting the initiation of outbursts of coal and gas, Rock Mech. Rock Eng. 47 (2014), pp. 1505-1510.

[2] Q. Tu, Y. Cheng, P. Guo, J. Jiang, L. Wang, and R. Zhang, Experiment study of coal and gasoutbursts related to gasenriched areas, Rock Mech. Rock Eng. (2016), pp. 1-13. 
[3] R.D. Lama and J. Bodziony, Management of outburst in underground coal mines, Int. J. Coal Geol. 35 (1998), pp. $83-115$.

[4] C. Mark, Coal bursts in the deep longwall mines of the United States, Int. J. Coal Sci. Technol. 3 (2016), pp. 1-9.

[5] M.B.D. Aguado and C.G. Nicieza, Control and prevention of gas outbursts in coal mines, Riosa-Olloniego coalfield, Spain, Int. J. Coal Geol. 69 (2007), pp. 253-266.

[6] N. Skoczylas and M. Wierzbicki, Evaluation and management of the gas and rock outbursthazard in the light of international legal regulations, Arch. Min. Sci. 59 (2014), pp. 1119-1129.

[7] D. Li, Mining thin sub-layer as self-protective coal seam to reduce the danger of coal and gas outburst, Nat. Hazards 71 (2014), pp. 41-52.

[8] K. Noack, Control of gas emissions in underground coal mines, Int. J. Coal Geol. 35 (1998), pp. 57-82.

[9] B.B. Beamish and P.J. Crosdale, Instantaneous outbursts in underground coal mines: An overview and association with coal type, Int. J. Coal Geol. 35 (1998), pp. 27-55.

[10] S.K. Choi and M.B. Wold, A mechanistic study of coal and gas outbursts, in Proceedings 38th US Rock Mechanics Symposium, Washington, DC, 2001, pp. 343-350.

[11] J.G. Singh, A mechanism of outbursts of coal and gas, Min. Sci. Technol. 1 (1984), pp. 269-273.

[12] L. Dongji, L. Chengwu, Z. Zhang, and Y. Zhang, Coal and gas outburst mechanism of the 'Three Soft' coal seam in western Henan, Min. Sci. Technol. 20 (2010), pp. 712-717.

[13] K.P. Chen, A new mechanistic model for prediction of instantaneous coal outbursts-dedicated to the memory of Prof. Daniel D. Joseph, Int. J. Coal Geol. 87 (2011), pp. 72-79.

[14] M.B. Wold, L.D. Connell, and S.K. Choi, The role of spatial variability in coal seam parameters on gas outburst behaviour during coal mining, Int. J. Coal Geol. 75 (2008), pp. 1-14.

[15] X. He, W. Chen, B. Nie, and M. Zhang, Classification technique for danger classes of coal and gas outburst in deep coal mines, Saf. Sci. 48 (2010), pp. 173-178.

[16] Y. Miao, J. Zhang, H. Zhang, X. Ma, and Z. Zhao, Coal and gas outburst prediction combining a neural network with the dempster-shafter evidence. Proceedings of the 5th International Symposium on Neural Networks: Advances in Neural Networks (2008), pp. 822-829.

[17] Z. Ruilin and I.S. Lowndes, The application of a coupled artificial neural network and fault tree analysis model to predict coal and gas outbursts, Int. J. Coal Geol. 84 (2010), pp. 141-152.

[18] Z. Li, E. Wang, J. Ou, and Z. Liu, Hazard evaluation of coal and gas outbursts in acoal-mine roadway based on logistic regression model, Int. J. Rock Mech. Min. 80 (2015), pp. 185-195.

[19] D. Li and Y. Cheng, Evaluation of gas control ability of a coal and gas outburst mine, Energy Sources, Part A 36 (2014), pp. 2401-2409.

[20] J.A. Hudson, Rock Engineering Systems: Theory and Practice, Ellis Horwood, Chichester, 1992.

[21] State Administration of Coal Mine Safety. A Compilation of Mine Gas Identifications in China, 2008. (In Chinese).

[22] R. Lama and A. Saghafi, Overview of gas outbursts and unusual emissions, Coal Operators' Conference 2002.

[23] A.R. Scott, Hydrogeologic factors affecting gas content distribution in coal beds, Int. J. Coal Geol. 50 (2002), pp. 363-387.

[24] A.R. Scott and W.R. Kaiser, Factors affecting gas-content distribution in coal beds: A review, AAPG Rocky Mountain Section Meeting, Billings, Montana, July $28-31$ 1996, Expanded Abstracts Volume. pp. 101-106.

[25] Y.P. Cheng, H.F. Wang, L. Wang, and H.X. Zhou, Theories and Engineering Applications on Coal Mine Gas Control, China University of Mining and Technology Press, Xuzhou, 2010.

[26] C. Wu, Z. Chen, C. Wang, and W. Jiang, The enrichment characteristics and geological controlling factors of coalbed methane occurrence in Laochang area, Yumnan Province, J. Coal Sci. Eng. (Chin). 18 (2012), pp. 355-361.

[27] C. Wu, Z. Ou, Q. Feng, and J. Zhang, CBM geology conditions study of Gemudi syncline, western Guizhou Province, J. Coal Sci. Eng. (Chin). 16 (2010), pp. 288-291.

[28] G. Yin, X. Li, H. Zhao, X.Q. Li, and X.F. Jing, Experimental study of effect of gas pressure on gas seepage of outburst coal, Chin. J. Rock Mech. Eng. 28 (2009), pp. 697-702. (In Chinese).

[29] S. Wang, D. Elsworth, and J. Liu, Mechanical behavior of methane infiltrated coal: The roles of gas desorption, stress level and loading rate, Rock Mech. Rock Eng. 46 (2013), pp. 945-958.

[30] L. Langmuir, The constitution and fundamental properties of solids and liquids. Part I. Solids, J. Am. Chem. Soc. 38 (1916), pp. 2221-2295.

[31] A. Busch, Y. Gensterblum, B.M. Krooss, and R. Littke, Methane and carbon dioxide adsorption-diffusion experiments on coal: Upscaling and modeling, Int. J. Coal Geol. 60 (2004), pp. 151-168.

[32] G. Yin, C. Jiang, J.G. Wang, J. Xu, D. Zhang, and G. Huang, A new experimental apparatus for coal and gas outburst simulation, Rock Mech. Rock Eng. 49 (2016), pp. 2005-2013.

[33] W.H. Somerton, I.M. Söylemezoḡlu, and R.C. Dudley. Effect of stress on permeability of coal, Int. J. Rock Mech. Min. Sci. Geomech. Abstr 12 (1975), pp. 129-145.

[34] S. Durucan and J.S. Edwards, The effects of stress and fracturing on permeability of coal, Mining Science and Technology 3 (1986), pp. 205-216.

[35] G.E. Eddy, C.T. Rightmire, and C.W. Byrer, Relationship of methane content of coal rank and depth: Theoretical $v$ s. observed. SPE Unconventional Gas Recovery Symposium, Society of Petroleum Engineers, 1982. 
[36] M. Mastalerz, A. Drobniak, D. Strąpoć, and W.S. Acosta, Variations in pore characteristics in high volatile bituminous coals: Implications for coal bed gas content, Int. J. Coal Geol. 76 (2008), pp. 205-216.

[37] P.J. Crosdale, B.B. Beamish, and M. Valix, Coalbed methane sorption related to coal composition, Int. J. Coal Geol. 35 (1998), pp. 147-158.

[38] J.H. Levy, S.J. Day, and J.S. Killingley, Methane capacities of Bowen Basin coals related to coal properties, Fuel 76 (1997), pp. 813-819.

[39] J.F. Unsworth, C.S. Fowler, and L.F. Jones, Moisture in coal: 2. Maceral effects on pore structure, Fuel (1989), pp. $18-26$.

[40] M.M. Faiz, N.I. Aziz, A.C. Hutton, and B.J. Jones, Porosity and gas sorption capacity of some eastern Australian coals in relation to coal rank and composition, in Coalbed Methane Symposium, Townsville, 1992, pp. 19-21.

[41] X. Jiang, Y. Mei, L. Bobo, and T. Yunqi, Experimental study of relationships between metamorphic grade, pore characteristics and permeability of coal, Chin. J. Rock Mech. Eng. 31 (2012), pp. 681-687.

[42] J. Shepherd, L.K. Rixon, and L. Griffiths, Outbursts and geological structures in coal mines: A review, Int. J. Rock Mech.Min. Sci. Geornech. Abstr. 18 (1981), pp. 267-283.

[43] L. Huoyin, Major and minor structural features of a bedding shear zone along a coal seam and related gas outburst, Pingdingshan coalfield, northern China, Int. J. Coal Geol. 47 (2001), pp. 101-113.

[44] M. Li, B. Jiang, S. Lin, F. Lan, and J. Wang, Structural controls on coalbed methane reservoirs in Faer coal mine, southwest China, J. Earth Sci-Chin. 24 (2013), pp. 437-448.

[45] B. Jiang, Z. Qu, G.G.X. Wang, and M. Li, Effects of structural deformation on formation of coalbed methane reservoirs in Huaibei coalfield, China, Int. J. Coal Geol. 82 (2010), pp. 175-183.

[46] Y. Cao, A. Davis, R. Liu, X. Liu, and Y. Zhang, The infuence of tectonic deformation on some geochemical properties of coals-a possible indicator of outburst potential, Int. J. Coal Geol. 53 (2013), pp. 69-79.

[47] X. Chen and Y. Cheng, Influence of the injected water on gas outburst disasters in coal mine, Nat. Hazards 76 (2015), pp. 1093-1109.

[48] B. Lin, T. Liu, Y. Zhou, Z. Zhang, and F. Yan, Variation of methane adsorption property of coal after the treatment of hydraulic slotting and methane pre-drainage: A case study, J. Nat. Gas Sci. Eng. 20 (2014), pp. $396-406$.

[49] G. Xiugen, W. Jiachen, and L. Yude, Water resistant features of high-risk outburst coal seams and standard discriminant model of mining under water-pressure, Min. Sci. Tech. 20 (2010), pp. 797-802.

[50] T. Jia, W. Wang, and Z. Zhang, Influence of fault strike on gas outburst under modern tectonic stress field, J. Min. Saf. Eng. 30 (2013), pp. 930-934. (In Chinese).

[51] Z. Meng, J. Zhang, and R. Wang, In-situ stress, pore pressure and stress-dependent permeability in the southern Qinshui Basin, Int. J. Rock Mech. Min. 48 (2011), pp. 122-131.

[52] J.D.S. George and M.A. Barakat, The change in effective stress associated with shrinkage from gas desorption in coal, Int. J. Coal Geol. 45 (2001), pp. 105-113.

[53] J.A. Hudson and J.L. Hudson, Establishing potential behavioural modes of rock engineering systems by computer simulation of interaction matrix energy flux, Int. J. Rock Mech. Min. Sci. Geomech. Abstr. 30 (1993), pp. 457-468.

[54] J.A. Hudson and J.P. Harrison, A new approach to studying complete rock engineering problems, Q. J. Eng. Geol. 25 (1990), pp. 93-105.

[55] D. Rozos, G.D. Bathrellos, and H.D. Skillodimou, Comparison of the implementation of rock engineering system and analytic hierarchy process methods, upon landslide susceptibility mapping, using GIS: A case study from the eastern Achaia county of Peloponnesus, Greece, Environ. Earth Sci. 63 (2011), pp. 49-63.

[56] M.Z. Naghadehi, R. Jimenez, and R. KhaloKakaie, A new open-pit mine slope instability index defined using the improved rock engineering systems approach, Int. J. Rock Mech. Min. 61 (2013), pp. 1-14.

[57] J.P. Latham and P. Lu, Development of an assessment system for the blastability of rock masses, Int. J. Rock Mech. Min. 36 (1999), pp. 41-55.

[58] R. Rafiee, M. Ataei, R. Khalokakaie, and S.M.E. Jalali, Determination and assessment of parameters influencing rock mass cavability in block caving mines using the probabilistic rock engineering system, Rock Mech. Rock Eng. 48 (2015), pp. 1207-1220.

[59] O. Frough and S.R. Torabi, An application of rock engineering systems for estimating TBM downtimes, Eng. Geol. 157 (2013), pp. 112-123.

[60] D.N. Whittles, I.S. Lowndes, S.W. Kingman, C. Yates, and S. Jobling, Influence of geotechnical factors on gas flow experienced in a UK longwall coal mine panel, Int. J. Rock Mech. Min. 43 (2006), pp. $369-387$.

[61] S.J. Peng, J. Xu, H.W. Yang, and D. Liu, Experimental study on the influence mechanism of gas seepage on coal and gas outburst disaster, Saf. Sci. 50 (2012), pp. 816-821.

[62] V. Hudecek, Analysis of safety precautions for coal and gas outburst-hazardous strata, J. Min. Sci. 44 (2008), pp. $464-472$.

[63] S. Valliappan and Z. Wohua, Role of gas energy during coal outbursts, Int. J. Numer. Methods Eng. 44 (1999), pp. $875-895$.

[64] C. Wang, J. Feng, J. Liu, M. Wei, C. Wang, and B. Gong, Direct observation of coal-gas interactions under thermal and mechanical loadings, Int. J. Coal Geol. 131 (2014), pp. 274-287.

[65] J.X. Wei and B.Q. Lin, Mechanism of Coal or Rock Dynamic Disasters and the Comprehensive Management Technology, Science Press, Beijing, 2009. 
[66] V.N. Odintsev, Sudden outburst of coal and gas - Failure of natural coal as a solution of methane in a solid substance, J. Min. Sci. 33 (1997), pp. 508-516.

[67] K. Wang, X. Ma, S. Jiang, Z. Wu, H. Shao, and X. Pei, Application study on complex wetting agent for dust-proof after gas drainage by outburst seams in coal mines, Int. J. Min. Sci. Tech. 26 (2016), pp. 669-675.

[68] H. Zhou, H. Dai, and C. Ge, Quality and quantity of pre-drainage methane and responding strategies in Chinese outburst coal mines, Arab. J. Geosci. 9 (2016), pp. 1-14.

[69] L. Yanwei, W. Qian, C. Wenxue, L. Mingju, and H. Mitri, Enhanced coalbed gas drainage based on hydraulic flush from floor tunnels in coal mines, Int. J. Min., Reclam. Env. 30 (2016), pp. 37-47.

[70] B. Lin, F. Yan, C. Zhu, Y. Zhou, Q. Zou, C. Guo, and T. Liu, Cross-borehole hydraulic slotting technique for preventing and controlling coal and gas outbursts during coal roadway excavation, J. Nat. Gas Sci. Eng 26 (2015), pp. 518-525.

[71] Q. Li, B. Lin, and C. Zhai, A new technique for preventing and controlling coal and gas outburst hazard with pulse hydraulic fracturing: a case study in Yuwu coal mine, China, Nat. Hazards 75 (2015), pp. 2931-2946.

[72] H. Liu, H. Liu, and Y. Cheng, The elimination of coal and gas outburst disasters by ultrathin protective seam drilling combined with stress-relief gas drainage in Xinggong coalfield, J. Nat. Gas Sci. Eng. 21 (2014), pp. 837-844.

[73] Q. Sun, J. Zhang, Q. Zhang, W. Yin, and D. Germain, A protective seam with nearly whole rock mining technology for controlling coal and gas outburst hazards: A case study, Nat. Hazards 84 (2016), pp. 1793-1806. 